\title{
Comparison of Immunological Characteristics of Mesenchymal Stem Cells Derived from Human Embryonic Stem Cells and Bone Marrow
}

\author{
Xin Fu, PhD, ${ }^{1, *}$ Yao Chen, PhD, ${ }^{2, *}$ Fang-Nan Xie, MD, ${ }^{1}$ Ping Dong, MSc, ${ }^{1}$ Wen-bo Liu, BDS, ${ }^{1}$ \\ Yilin Cao, MD, PhD, ${ }^{1,2}$ Wen-Jie Zhang, MD, PhD, ${ }^{2, \#}$ and Ran Xiao, PhD, DDS ${ }^{1, \#}$
}

\begin{abstract}
Mesenchymal stem cell (MSC) has great potential for both regenerative medicine and immunotherapy due to its multipotency and immunomodulatory property. The derivation of MSCs from human tissues involves an invasive procedure and the obtained MSCs often suffer from inconsistent quality. To overcome these issues, the approaches of deriving a highly potent and replenishable population of MSCs from human embryonic stem cells (hESCs) were established. However, few studies compared the immunological characteristics of MSCs derived from hESCs with tissue-derived MSCs or demonstrated differences and the underlying mechanisms. Here, we differentiated H9 hESCs into MSC-like cells (H9-MSCs) through an embryoid body outgrowth method and compared the immunological characteristics of H9-MSCs with bone marrow-derived MSCs (BMSCs). Both sources of derived cells exhibited typical MSC morphologies and surface marker expressions, as well as multipotency to differentiate into osteogenic and adipogenic lineages. A immunological characterization study showed that H9-MSCs and BMSCs had similar immunoprivileged properties without triggering allogeneic lymphocyte proliferation as well as equivalent immunosuppressive effects on T-cell proliferation induced by either cellular or mitogenic stimuli. Flow cytometry analysis revealed a lower expression of human major histocompatability complex class II molecule human lymphocyte antigen (HLA)-DR and a higher expression of coinhibitory molecule B7-H1 in H9-MSCs than in BMSCs. Interferon gamma (IFN- $\gamma$ ) is a proinflammatory cytokine that can induce the expression of HLA class II molecules in many cell types. Our results showed that pretreatment of $\mathrm{H} 9-\mathrm{MSC}$ and BMSCs with IFN- $\gamma$ did not change their immunogenicity and immunosuppressive abilities, but increased the difference between H9-MSCs and BMSCs for their expression of HLA-DR. Further detection of expression of molecules involved in IFN- $\gamma$ signaling pathways suggested that the lower expression of HLA-DR in H9-MSCs could be partially attributed to the lower expression and the less nuclear translocation of its transcriptional factor CIITA. The present study provides evidence that the hESC-derived MSCs share similar immunogenicity and immunosuppressive abilities with BMSCs, but differ in the expression profile of immunological markers and the responsiveness to certain inflammatory cytokines, which suggests that H9-MSCs could be a safe and efficient candidate for MSC treatment in patients with inflammatory disorders.
\end{abstract}

\section{Introduction}

$\mathbf{M}$ ESENCHYMAL STEM CELLS (MSCS) are multipotent nonhematopoietic progenitors present in the stromal fraction of adult and fetal tissues, in particular, from the bone marrow and adipose. ${ }^{1-4}$ Apart from their multilineage differentiation potentials, the immunoprivileged and immunomodulatory properties of MSCs have led them to be attractive candidates for cell therapy and regenerative medicine., Nevertheless, loss of potency, inconsistent quality, and invasive procedure involved in cell isolation severely limit the use of MSCs in clinical applications. ${ }^{7-9}$ Therefore, the derivation of MSCs from other consistent sources has been considered as an alternative. The successful isolation and in vitro culture of human embryonic stem cells (hESCs), being capable of unlimited self-renewal and differentiation

\footnotetext{
${ }^{1}$ Research Center of Plastic Surgery Hospital, Chinese Academy of Medical Sciences, Peking Union Medical College, Beijing, P.R. China.

${ }^{2}$ Stem Cell Laboratory, Department of Plastic and Reconstructive Surgery, Shanghai 9th People's Hospital, Shanghai Jiao Tong University School of Medicine, Shanghai, P.R. China.

*These two authors contributed equally to this work.

${ }^{\#}$ These two authors contributed equally to this work.
} 
into all cell lineages of the body, ${ }^{10}$ opened a new avenue for MSC derivation. There are well-established approaches for the differentiation of hESCs into functional MSCs with immunomodulatory properties. ${ }^{11-15}$ However, the differences between hESC-derived MSCs and tissue-derived MSCs in their immunological characteristics and the underlying mechanisms have not been well defined as yet.

The immunoprivileged status of MSCs was partly due to the lack of expression of major histocompatibility complex class II (MHC-II) and costimulatory molecules. ${ }^{16}$ The MHCII antigen is constitutively expressed on professional antigenpresenting cells (APC). It binds peptide fragments derived from pathogens and displays them on the cell surface for recognition by the appropriate $\mathrm{T}$ cells. ${ }^{16,17}$ The best-studied costimulatory molecules belong to the B7 family, which consists of seven known members: CD80 (B7.1), CD86 (B7.2), B7-H1 (programmed death-1 ligand [PD-L1]), B7-H2 (inducible costimulator ligand), B7-DC (programmed death-2 ligand [PD-L2]), B7-H3, and B7-H4. They bind to receptors on lymphocytes and regulate immune responses by directing either costimulatory or coinhibitory signals. ${ }^{18}$ Interferon gamma (IFN- $\gamma$ ), a major proinflammatory cytokine secreted by activated T cells and natural killer (NK) cells, ${ }^{19}$ can markedly stimulate or increase the expression of MHC-II molecules in many cell types and control the APC function of MSCs by regulating the expression of class II transactivator (CIITA), the master regulator of MHC-II. ${ }^{16,19-21}$ However, the influence of IFN- $\gamma$ on the immunogenicity of MSCs is still surrounded by controversy. $^{22-26}$

The immunomodulatory properties of MSCs have been extensively studied both in vitro and in vivo. ${ }^{27-29}$ In vitro, MSCs act in a dose-dependent manner to suppress T-lymphocyte proliferation induced by cellular or nonspecific mitogenic stimuli. ${ }^{30,31}$ Other attempts using MSC in vivo studies have demonstrated that MSCs could promote engraftment of $\mathrm{CD} 34+$ hematopoietic stem cells, ${ }^{32}$ reduce incidence of graftversus-host diseases in patients receiving allogenic transplants, ${ }^{33}$ ameliorate autoimmune diseases, ${ }^{34,35}$ and prevent the rejection of allogeneic skin grafts. ${ }^{36}$ Direct cell contact with immune cells ${ }^{37}$ and soluble factors produced by MSCS, such as IL- $6,{ }^{38}$ TGF- $\beta,{ }^{39,40}$ hepatocyte growth factor, ${ }^{41}$ nitric oxide, $^{42}$ indoleamine 2,3-dioxygenase, ${ }^{43,44}$ and prostaglandin $\mathrm{E} 2{ }^{45,46}$ have been implicated in the mechanisms of MSCmediated immunosuppression.

In this study, we differentiated H9 hESCs into MSC-like cells (H9-MSCs) through an embryoid body (EB) outgrowth method. The immunological characteristics of H9-MSCs were characterized and compared to bone marrow-derived MSCs (BMSCs) with or without IFN- $\gamma$ treatment. Moreover, the expression of genes encoding components in IFN- $\gamma$ signaling pathways in H9-MSCs and BMSCs was investigated after IFN- $\gamma$ treatment. Our data may provide additional insights into the responsiveness of H9-MSCs and BMSCs under inflammatory conditions after in vivo transplantation.

\section{Materials and Methods}

Culture and differentiation of H9 hESCs into MSCs (H9-MSCS)

The H9 hESC line was obtained from the WiCell Research Institute under a Materials Transfer Agreement (No. 11W0039) and cultured on mitomycin C (Roche)-inactivated mouse embryonic fibroblast, as previously described. ${ }^{47}$ Cells were maintained in the hESC medium: DMEM/F-12 (Invitrogen), 20\% knockout serum replacement (Invitrogen), $4 \mathrm{ng} / \mathrm{mL}$ fibroblast growth factor-2 (FGF-2; Invitrogen), $1 \mathrm{mM}$ L-glutamine (Invitrogen), $1 \%$ nonessential amino acid (Invitrogen), and $0.1 \mathrm{mM} \beta$-mercaptoethanol (Sigma). Derivation of H9-MSCs was achieved following published protocol. $^{48}$ Briefly, EBs were formed by mass suspension of hESCs in a hESC culture medium without FGF-2 for 10 days. The EBs were seeded onto a gelatin-coated plate for adherent culture in the MSC growth medium: DMEM supplemented with $10 \%$ fetal bovine serum (FBS) and $1 \mathrm{ng} / \mathrm{mL}$ FGF-2. The cells at this initial passage (P0) were kept for 2 weeks followed by subsequent normal subculture. Three independent derivations of H9-MSCs were conducted.

\section{Isolation and culture of BMSCs}

Bone marrow aspirates were collected from iliac crest of five patients who receiving plastic surgery with informed consent. BMSCs were isolated by a gradient centrifugation using Ficoll-Paque PLUS (GE Healthcare) and cultured in the MSC culture medium containing DMEM (Invitrogen) with 10\% FBS (Lonza). All studies were conducted with approval from the ethics committee of Plastic Surgery Hospital.

\section{Immunofluorescence staining}

H9 hESCs were assessed by immunofluorescence staining for expression of hESC-specific markers OCT4 and SSEA-4 following protocols described previously. ${ }^{47}$ Mouse antihuman OCT4 (611010; BD) and SSEA4 (560073; BD) were used as primary antibodies and goat anti-mouse AlexaFluor-594 IgG and Alexa-Fluor-488 IgG (Invitrogen) were used as secondary antibodies, respectively. The cells were mounted with a solution containing DAPI (Invitrogen) and imaged with a Nikon TE2000-S microscope.

\section{Osteogenic and adipogenic differentiation of human MSCS}

H9-MSCs P5 and BMSCs P3 were subjected to osteogenic and adipogenic differentiation following published protocols. ${ }^{49}$ After 4 weeks in culture, H9-MSCs and BMSCs were stained by Alizarin red after osteogenic differentiation and by Oil red after adipogenic differentiation.

\section{Flow cytometry analysis}

The surface marker expressions of H9-MSCs and BMSCs were characterized using the Stemflow ${ }^{\mathrm{TM}}$ human MSC analysis kit (BD) following the manufacturer's instructions. Specific primary antibodies included CD44-PE, CD73-APC, CD90-FITC, CD105-PerCP.Cy5.5, and a negative antibody cocktail (CD31-PE, CD45-PE, CD71-PE, and CD117-PE). H9-MSCs at P5 and BMSCs at P3 were treated with IFN- $\gamma$ (0 U, 10 U, $100 \mathrm{U}, 400 \mathrm{U}, 1000 \mathrm{U}$, or $4000 \mathrm{U} / \mathrm{mL}$ ) for $72 \mathrm{~h}$ and then incubated with primary antibodies targeting human lymphocyte antigen (HLA) class I antigens (HLA-A,B,CAPC), HLA class II molecule (HLA-DR-APC), costimulatory molecule (CD40-PE), and B7 family members (CD80-APC, CD86-FITC, B7-H1-APC, B7-H2-PE, B7-H3-PE, B7-H4-PE, and B7-DC-APC), respectively (Biolegend). The data with 
$1 \times 10^{4}$ events per cell sample were generated by FACSAria ${ }^{\mathrm{TM}}$ II (BD) and analyzed using FlowJo v7.6.1 software (Tree Star).

\section{Mix lymphocyte reaction and mitogen stimulation assay}

Peripheral blood mononuclear cells (PBMC) were fractionated from peripheral blood of healthy volunteers by FicollPaque PLUS (GE Healthcare), as reported previously. ${ }^{49}$ PBMCs isolated from two unrelated individuals were named as PBMC1 and PBMC2. The untreated PBMCs were used as responders $\left(\mathrm{PBMC}^{\mathrm{r}}\right)$. The inactivated PBMCs $\left(\mathrm{PBMC}^{\mathrm{s}}\right)$, H9MSCs, and BMSCs by $25 \mu \mathrm{g} / \mathrm{mL}$ of mitomycin $\mathrm{C}$ for $20 \mathrm{~min}$ at $37^{\circ} \mathrm{C}$ were used as stimulators. For the one-way mix lymphocyte reaction (MLR), $1 \times 10^{5}$ inactivated $\mathrm{H} 9$-MSCs or BMSCs were cocultured with $1 \times 10^{5} \mathrm{PBMC1}^{\mathrm{r}}$ in the RPMI$1640+10 \%$ FBS medium within the 96-well plates (Corning). $\mathrm{PBMC}^{\mathrm{r}}$ cocultured with $\mathrm{PBMC} 2^{\mathrm{s}}$ were used as the positive control. For two-way MLR, $1 \times 10^{5} \mathrm{PBMC1}^{\mathrm{r}}$ and $1 \times 10^{5}$ $\mathrm{PBMC}^{\mathrm{r}}$ were mixed and cocultured with inactivated H9MSCs or BMSCs at three different ratios $(1: 1,10: 1$, and 100:1), respectively, for 5 days. The proliferations of $\mathrm{PBMC}^{\mathrm{r}}$ were assessed by the CellTiter 96 Aqueous Nonradioactive Cell Proliferation Assay kit (Promega), and the absorbance at $490 \mathrm{~nm}$ was measured in the PerkinElmer EnSpire ${ }^{\mathrm{TM}}$ Multimode Plate Reader. The proliferation index (PI) for one-way MLR was calculated as follows: $\mathrm{PI}_{\text {one-way }}=$ $\frac{\text { Absorbance }\left(\mathrm{PBMC1}^{\mathrm{r}}+\mathrm{MSC}\right)-\text { Absorbance }(\mathrm{MSC})}{\text { Absorbance }\left(\mathrm{PBMC1}^{\mathrm{r}}+\mathrm{PBMC}^{\mathrm{s}}\right)-\text { Absorbance }\left(\mathrm{PBMC}^{\mathrm{s}}\right)}, \mathrm{PI}=1$ is considered as immunogenic to induce $\mathrm{PBMC}^{\mathrm{r}}$ proliferation and PI for two-way MLR was calculated as $\mathrm{PI}_{\text {two-way }}=$

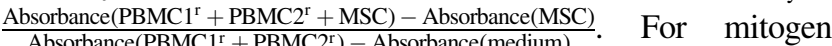
stimulation assay, inactivated H9-MSCs or BMSCs were cocultured with $1 \times 10^{5} \mathrm{PBMC}^{\mathrm{r}}$ at two different ratios $(1: 100$ and $1: 10)$ in a 96-well plate and stimulated by $10 \mu \mathrm{g} / \mathrm{mL}$ phytohemagglutinin (PHA; Sigma) for $72 \mathrm{~h}$. $\mathrm{PBMC}^{\mathrm{r}}$ without PHA stimulation were used as the background control. PI was calculated as follows: $\mathrm{PI}_{\mathrm{PHA}}=$ $\frac{\text { Absorbance }\left(\mathrm{PHA} \text { treated } \mathrm{PBMC} \mathrm{C}^{\mathrm{r}}+\mathrm{MSC}\right)-\text { Absorbance }(\mathrm{MSC})}{\text { Absorbance }\left(\mathrm{PBMC}^{\mathrm{r}}\right)-\text { Absorbance(Medium) }}$. To test the effects of IFN- $\gamma$ on the immunogenicity and immunomodulatory properties of H9-MSCs and BMSCs, MLR and mitogen stimulation assays were performed as above with H9-MSCs and BMSCs pretreated by IFN- $\gamma(10 \mathrm{U} / \mathrm{mL}, 72 \mathrm{~h})$ before the inactivation. All experiments were conducted thrice with different PBMCs and MSCs in triplicate.

\section{Conventional and real-time polymerase chain reaction}

For cDNA synthesis, 500 ng of RNA was reverse transcribed using the M-MLV reverse transcriptase (Invitrogen) following the manufacturer's instructions. The conventional polymerase chain reaction (PCR) for pluripotent markers $(O C T 4, N A N O G)$ and three germ layer markers (NEUROD1, $B R A C H Y U R Y$, and AFP) was performed on Biorad DNA Engine, and the $\beta$-actin gene was used as a control. The real-time PCR was performed using the Fast SYBR Green Master Kit and LightCycler 480 system (Roche) according to the manufacturer's instructions, and the expression level of each gene was normalized to the expression of the housekeeping gene GAPDH. Primer sequences are summarized in Supplementary Table S1 (Supplementary Data are available online at www.liebertpub.com/tea).

\section{Western blotting for quantifying CIITA in cytoplasmic and nuclear protein extracts}

After incubation with 0,10 , or $1000 \mathrm{U} / \mathrm{mL}$ IFN- $\gamma$ for $72 \mathrm{~h}$, cytosol and nuclear protein fractions of H9-MSCs and BMSCs were separated and collected individually using the Cytosol-Nuclear protein extraction kit (Applygen; BJ). Western blottings were performed using mouse anti-human CIITA (SC-376174; Santa Cruz Biotechnology) and mouse anti-human GAPDH (TA081 ZSGB-BIO) as primary antibodies and the horseradish peroxidase-conjugated donkey anti-mouse IgG (Santa Cruz) as the secondary antibody. The SuperSignal West Pico Trial Kit (Thermo Scientific) was applied for protein detection. The intensity of individual band was quantified using ImageJ densitometry software.

\section{Statistical analysis}

Statistical analysis was performed using the SPSS statistical software package. The difference was evaluated by independent Student's $t$-test and one-way ANOVA test. A $p$-value of $<0.05$ was considered statistically significant.

\section{Results}

\section{Generation of H9-MSCs from H9 hESCs}

To generate MSC-like cells from H9 hESCs (H9-MSCs), H9 hESCs were differentiated through an EB outgrowth method. Undifferentiated H9 hESCs showed compact colony morphology with distinct borders (Fig. 1A) and positive staining for OCT4 and SSEA4 (Fig. 1B, C). After 10 days of suspension culture, H9 hESCs formed sphere-shaped EB aggregates (Fig. 1D). The EB aggregates could adhere to the gelatin-coated plate $24 \mathrm{~h}$ after plating. Fibroblast-like cells migrated outward from EB aggregates within $24-48 \mathrm{~h}$ of attachment (Fig. 1E). The outgrowing cells, which were named as H9-MSCs, could proliferate gradually and reach confluency after 1 week of culture. After 2 passages, cells became spindle shaped with homogeneous morphology (Fig. $1 F)$. The trends of expression changes of specified markers were analyzed using conventional and real-time PCR (Fig. $1 \mathrm{G}, \mathrm{H})$. Undifferentiated H9 hESCs expressed pluripotent markers (OCT4, NANOG), but did not express markers specific to three germ layers (NEUROD1, BRACHYURY, and $A F P$ ). Declining expression of $O C T 4$ with dramatic increase of NEUROD1, BRACHYURY, and AFP was observed in EBs. Expressions of $O C T 4, N A N O G$, and three germ layer markers were depleted in H9-MSCs after the second passage and exhibited a basal level in H9-MSCs at P5 $\left({ }^{*} p<0.05\right)$.

\section{Surface marker expression and differentiation potentials of H9-MSCs and BMSCs}

The cell surface marker expression of H9-MSCs and BMSCs was analyzed by flow cytometry analysis. During derivation, the majority of H9-MSCs gradually acquired fibroblast-like morphologies, lost SSEA-4 expression, and showed progressive acquisition of MSC-specific markers: CD90, CD105, and CD73 (Supplementary Fig. S1). Upon passage 5 (P5), more than $95 \%$ of H9-MSCs showed positive expression of CD90, CD105, CD73, and CD44, whereas uniformly negative for hematopoietic marker expression, including CD34, CD116, CD19, CD45, and HLA-DR (Fig. 

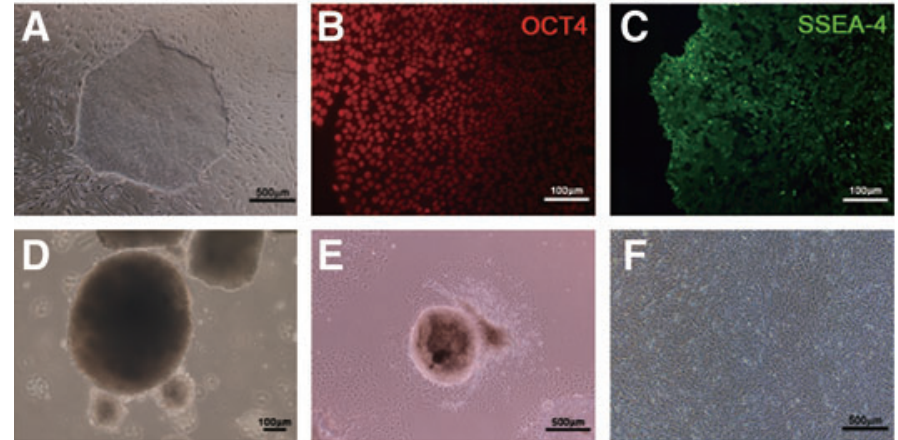

H
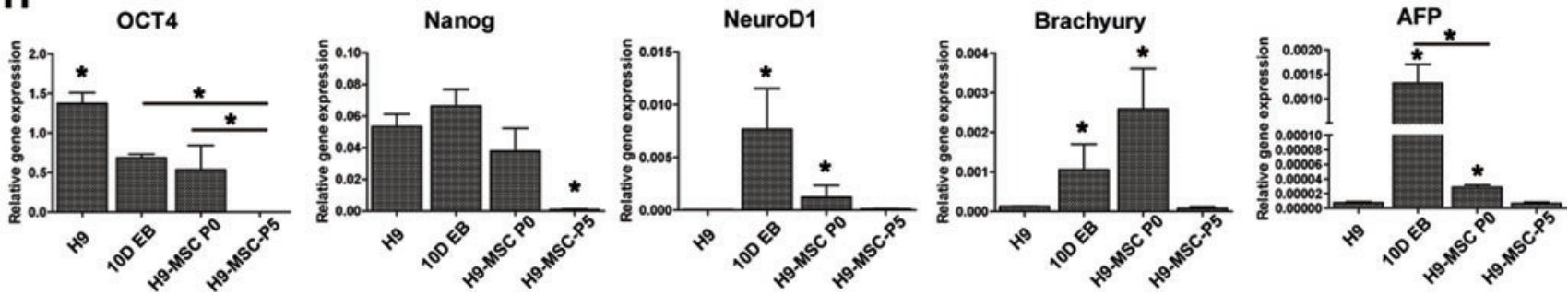

FIG. 1. Morphologies of H9-MSCs during derivation from H9 hESCs. (A) Morphology of undifferentiated H9 hESCs cultured on MEF. Scale bar indicates $500 \mu \mathrm{m}$. (B) Immunofluorescence staining of OCT4 and (C) SSEA-4 on H9 hESCs. Scale bar indicates $100 \mu \mathrm{m}$. (D) Formation of EB aggregates for 10 days in suspension culture. Scale bar indicates $100 \mu \mathrm{m}$. (E) Spindleshaped fibroblastic cells were outgrowing from the peripheral of adherent EB aggregates and (F) a typical H9-MSC culture after two passages were obtained. Scale bar indicates $500 \mu \mathrm{m}$. (G) Expression patterns of undifferentiated hESC-specific markers $(O C T 4, N A N O G)$ and three germ layer markers (ectoderm: NEUROD1, mesoderm: BRACHYURY, endoderm: AFP) in H9 hESCs after 10 passages (P10) and 20 passages (P20) on MEF; in EB samples after 5-day (5D) and 10-day (10D) cultures; and in H9MSCs from initial passage (P0) to fifth passage (P5) were presented. Housekeeping gene $\beta$-actin served as the internal control. (H) Real-time PCR analysis of the OCT4, NANOG, NEUROD1, BRACHYURY, and AFP in H9 hESCs, 10DEB, and H9-MSC at P0 and P10. ${ }^{*} p$-Value of <0.05. EB, embryoid body; hESCs, human embryonic stem cells; MEF, mouse embryonic fibroblast; MSCs, mesenchymal stem cells; PCR, polymerase chain reaction. Color images available online at www.liebertpub.com/tea

A
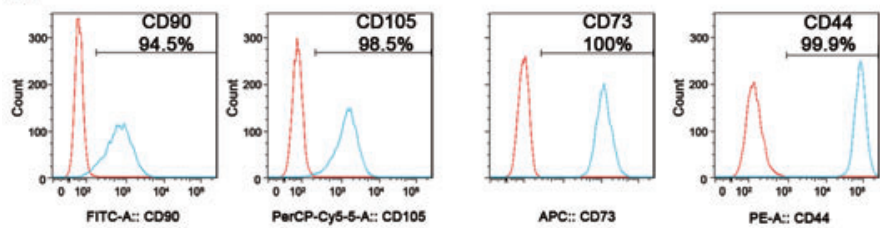

H9-MSC P5
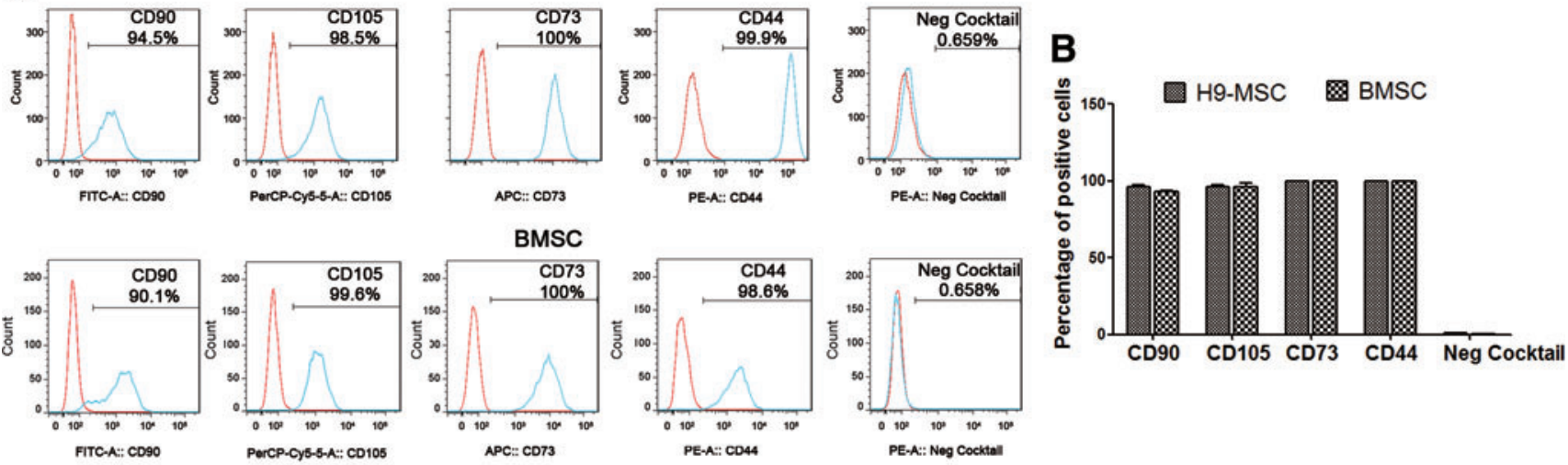

C

Osteogenesis
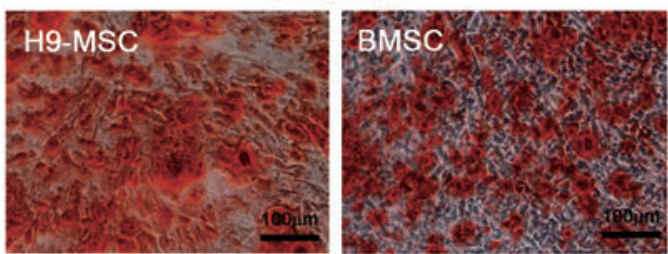

Alizarin Red
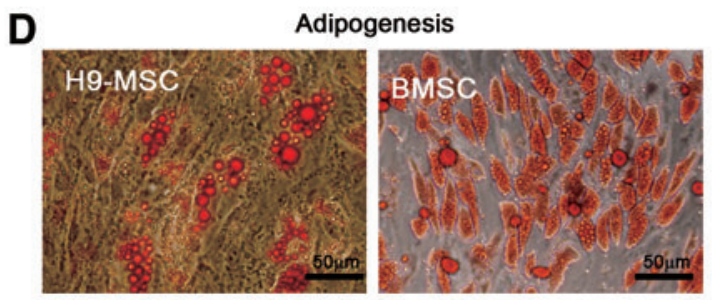

Oil Red

FIG. 2. Characterization of H9-MSCs and BMSCs by flow cytometry analysis and functional differentiation assays. (A) H9-MSCs expressed typical MSC-surface marker as BMSCs did. (B) Results summarized from three independent experiments demonstrated that the surface marker expression profiles of H9-MSCs were comparable to that of BMSCs. (C) Representative images of Alizarin red staining of bone nodule formation by H9-MSCs and BMSCs after differentiation in the osteogenic induction medium for 21 days. (D) Oil droplets could be observed in H9-MSCs and BMSCs after differentiation in the adipogenic induction medium for 21 days after Oil red staining. Scale bars represent $100 \mu \mathrm{m}$. BMSCs, bone marrow-derived MSCs. Color images available online at www.liebertpub.com/tea 
2A). No significant difference in the percentage of cells expressing these markers between H9-MSCs and BMSCs was detected (Fig. 2B). Functional differentiation assays demonstrated that both H9-MSCs and BMSCs showed a mineralized nodule formation after osteogenic differentiation (detected by Alizarin red staining, Fig. 2C) and accumulation of lipid droplets in the cytoplasm after adipogenic differentiation (visualized by Oil red staining, Fig. 2D).

\section{Effects of H9-MSCs and BMSCs in MLR and mitogen-stimulated cultures}

To compare the immunogenicity and immunomodulatory abilities of H9-MSCs and BMSCs, they were subjected to MLR and mitogen stimulation assays. Results of one-way MLR showed that both H9-MSCs $(\mathrm{PI}=0.20 \pm 0.12)$ and BMSCs $(\mathrm{PI}=0.29 \pm 0.08)$ did not elicit the proliferative response of PBMC1 (Fig. 3A). In two-way MLR assay, the suppression of PBMC proliferation by two types of MSCs was presented at a cell number of $1 \times 10^{3}\left({ }^{*} p<0.05\right)$ and more prominent at cell numbers of $1 \times 10^{4}$ and $1 \times 10^{5}$ $\left({ }^{\#} p<0.01\right)$ (Fig. 3B). Furthermore, both H9-MSCs and BMSCs suppressed PBMC proliferation induced by PHA stimulation in a dose-dependent fashion (Fig. 3C), in which inhibitory effects were only observed in groups coculturing $1 \times 10^{4} \mathrm{H} 9$-MSCs $(\mathrm{PI}=0.49 \pm 0.13)$ or BMSCs $(\mathrm{PI}=0.73 \pm$ $0.13)\left({ }^{\#} p<0.01\right)$, but not in groups coculturing $1 \times 10^{3} \mathrm{H} 9$ MSCs or BMSCs $(p>0.05)$. No significant difference between H9-MSCs and BMSCs for their suppressive effects $(p>0.05)$ was observed.

\section{Comparison of the expression of immunological markers in H9-MSCs and BMSCs}

The expression profiles of immunological markers in H9MSCs and BMSCs were analyzed using flow cytometry (Fig. 4).
Like BMSCs, the majority of H9-MSCs (>95\%) expressed HLA class I molecule HLA-ABC constitutively at high levels, but did not express HLA class II molecule HLA-DR $(<5 \%)$ (Fig. 4A, B). Neither H9-MSCs nor BMSCs expressed costimulatory molecules, including CD40 and B7 family members CD80, CD86, and B7-H2 (Fig. 4C, D). Expressions of coinhibitory B7 family members (B7-H1, B7-H3, and B7-DC), but not B7-H4, were detected in H9-MSCs and BMSCs in detail; majorities of H9-MSCs $(99.9 \%)$ and BMSCs $(100 \%)$ were positive for $\mathrm{B} 7-\mathrm{H} 3$ expression, whereas different portions of $\mathrm{H} 9-$ MSCs and BMSCs were positive for expression of B7-H1 $(69.9 \% \pm 4.5 \%$ and $27.6 \% \pm 0.4 \%)$ and B7-DC $(34.3 \% \pm 15.0 \%$ and $39.3 \% \pm 15.7 \%$ ), respectively (Fig. $4 \mathrm{E}, \mathrm{F}$ ). Results from three sets of individual experiments demonstrated that expressions of B7-H1 were significantly higher in H9-MSCs than in BMSCs, whereas the expressions of HLA-DR were significantly lower in H9-MSCs than in BMSCs $\left({ }^{*} p<0.05\right.$, Fig. $\left.4 \mathrm{G}\right)$.

\section{Immunological characteristics of H9-MSCs and BMSCs after IFN- $\gamma$ stimulation}

IFN- $\gamma$ is a well-known proinflammatory cytokine produced by activated $\mathrm{T}$ and NK cells and functions as a stimulator to induce expression of HLA class I and II molecules in many cell types. To compare the responsiveness of H9-MSCs and BMSCs to IFN- $\gamma$, the expressions of HLA-DR and other immunomodulatory molecules in H9-MSCs and BMSCs were evaluated by flow cytometry after different dosages of IFN- $\gamma$ treatment (Fig. 5). The percentages of HLA-DR-positive cells were increased in both H9-MSCs and BMSCs in a dosedependent manner after IFN- $\gamma$ stimulation, but were significantly higher in BMSCs than in H9-MSCs $\left({ }^{*} p<0.05\right)$ (Fig. $5 \mathrm{~A}$ ), and especially after $10 \mathrm{U} / \mathrm{mL}$ IFN- $\gamma$ treatment, the percentage of HLA-DR-positive cells in BMSCs dramatically increased to $73.0 \% \pm 9.1 \%$, which was 15 -fold higher than in
A

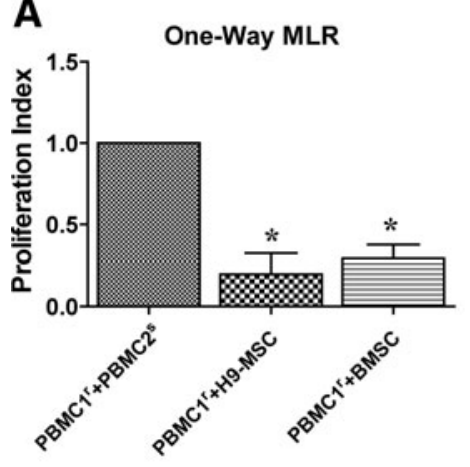

B

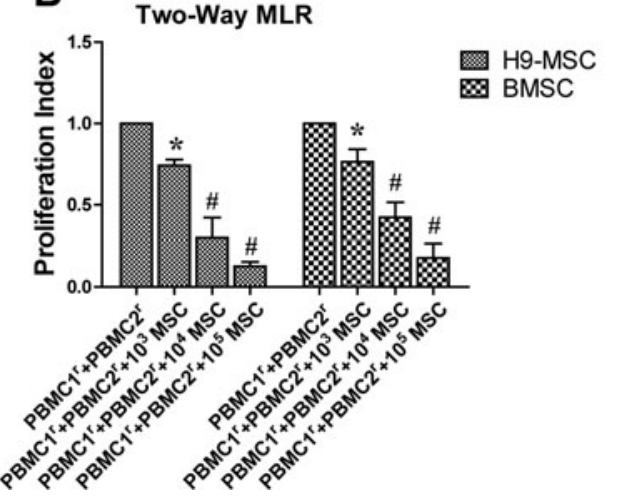

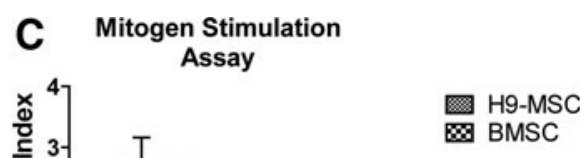

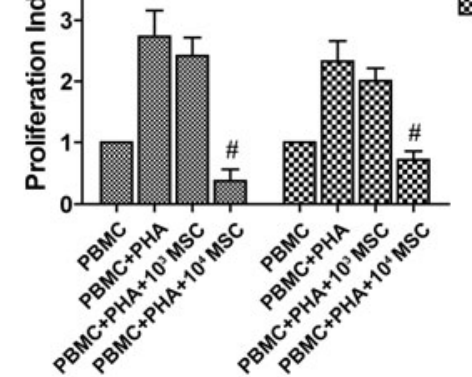

FIG. 3. Effects of H9-MSCs and BMSCs in MLR and mitogen-stimulated cultures. (A) H9-MSCs had low immunogenicity as BMSCs did and could not elicit lymphocyte proliferation. PBMC1 and PBMC2 represented PBMCs isolated from two unrelated individuals. Group coculturing $\mathrm{PBMC1}^{\mathrm{r}}$ and $\mathrm{PBMC}^{\mathrm{s}}$ was used as the positive control. (B) H9-MSCs could inhibit lymphocyte proliferation in two-way MLR culture in a cell number-dependent manner. Inhibitory effects of H9MSCs and BMSCs were observed with cell number at $10^{3}\left({ }^{*} p<0.05\right)$. The suppressive effects of H9-MSCs and BMSCs on PBMC proliferation were more pronounced with cell number at $10^{4}$ and $10^{5}\left({ }^{\#} p<0.01\right)$. No significant difference was observed between H9-MSCs and BMSCs for their immunosuppressive effects in two-way MLR assays. (C) H9-MSCs and BMSCs could inhibit lymphocyte proliferation by PHA stimulation. Inhibition effects were only observed in groups coculturing $1 \times 10^{4} \mathrm{H} 9$-MSCs $\left(\mathrm{PI}=0.49 \pm 0.13\right.$ ) or BMSCs $(\mathrm{PI}=0.73 \pm 0.13)$ with $1 \times 10^{5} \mathrm{PHA}$-activated PBMCs with a cell ratio of 1:10 $\left({ }^{\#} p<0.01\right)$, but not in groups coculturing H9-MSCs or BMSCs with PHA-stimulated PBMCs with a cell ratio of 1:100. MLR, mix lymphocyte reaction; PBMC, peripheral blood mononuclear cells; PHA, phytohemagglutinin; PI, proliferation index. 
H9-MSC

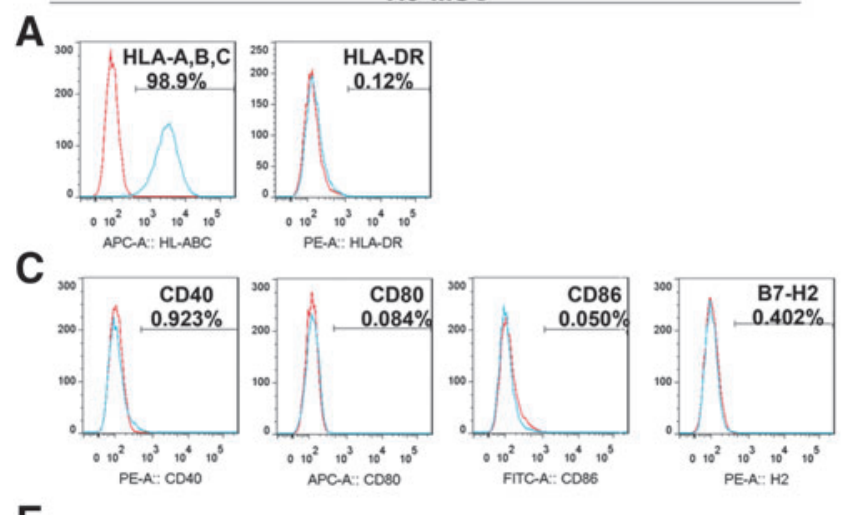

$\mathbf{E}$

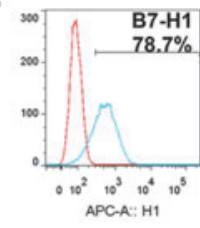

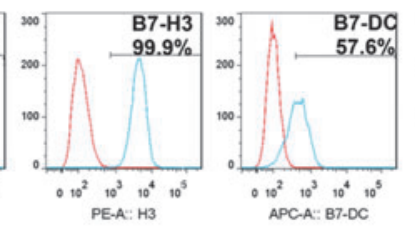

G

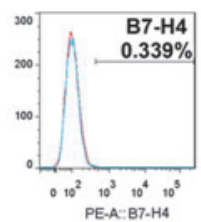

H9-MSC
BMSC

B

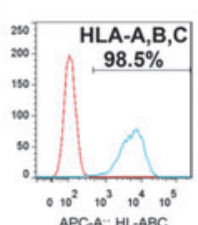

APC.A: HL-ABC $\quad$ PE-A: HLA-DR

D
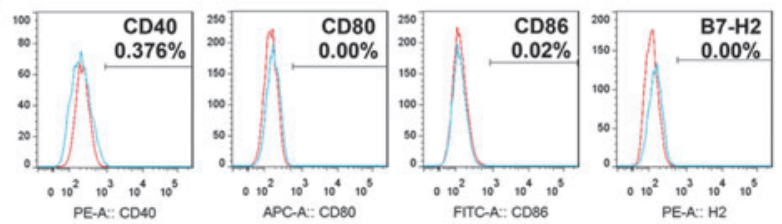

$\mathbf{F}$
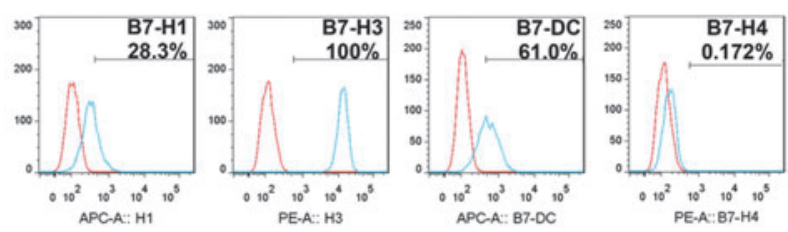

BMSC

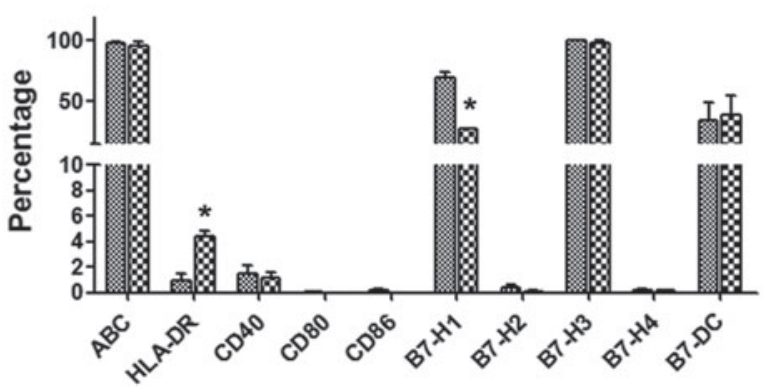

FIG. 4. Analysis of the expression of immunological molecules in H9-MSCs and BMSCs by flow cytometry. Consistently, a majority of (A) H9-MSCs (98.9\%) and (B) BMSCs (98.5\%) were stained positively for expression of HLA class I molecules HLA-A,B,C. The percentages of HLA-DR-positive cells were negligible $(<5 \%)$ in both H9-MSCs $(0.12 \%)$ and BMSCs $(3.74 \%)$. On the other hand, expressions of costimulatory molecules, including CD40 and B7 family members CD80, CD86, and B7-H2, were not detected in (C) H9-MSCs and (D) BMSCs. Expressions of coinhibitory B7 family members (B7-H1, B7H3, and B7-DC), but not B7-H4 were detected in H9-MSCs (E) and BMSCs (F). Results summarized from three independent experiments $(\mathbf{G})$ demonstrated that the percentages of HLA-DR-positive cells in H9-MSCs were significantly lower than in BMSCs, whereas percentages of B7-H1-positive cells in H9-MSCs were significantly higher than in BMSCs $(* p<0.05)$. No significant difference was observed in H9-MSCs and BMSCs for the percentage of cells expressing other immunological molecules. HLA, human lymphocyte antigen. Color images available online at www.liebertpub.com/tea

H9-MSCs $(4.7 \% \pm 1.7 \%)$. The percentage of HLA-DR-positive cells went up to $91.6 \% \pm 3.3 \%$ in BMSCs after $1000 \mathrm{U} / \mathrm{mL}$ IFN- $\gamma$ treatment, whereas gradually increased to $65.5 \% \pm 6.2 \%$ in H9-MSCs. Expressions of CD40 in H9-MSCs and BMSCs were elicited by IFN- $\gamma$ at $1000 \mathrm{U} / \mathrm{mL}$, and the percentage of CD40-positive cells in BMSCs was significantly higher than in H9-MSCs $(* p<0.05$, Fig. 5B). On the other hand, the percentage of cells expressing the coinhibitory molecule B7-DC was significantly higher in H9-MSCs than in BMSCs after IFN$\gamma$ treatment at $1000 \mathrm{U} / \mathrm{mL}(76.6 \% \pm 11.7 \%$ vs. $52.3 \% \pm 2.7 \%$, Fig. 5C), and B7-H1-positive cells in H9-MSCs were threefold higher than in BMSCs at $10 \mathrm{U} / \mathrm{mL}(63.3 \% \pm 10.9 \%$ vs. $20.8 \% \pm 5.9 \%$, Fig. 5D). In addition, both H9-MSCs and BMSCs constitutively expressed HLA-ABC and B7-H3 and were negative for the expressions of costimulatory molecules CD80, CD86, B7-H4, and B7-H2, regardless of the IFN- $\gamma$ treatment (Supplementary Fig. S2).
To clarify whether different expressions of immunological markers in H9-MSCs and BMSCs in response to IFN- $\gamma$ would differentially affect the functional capacity of H9-MSCs and BMSCs to inhibit T-cell proliferation, H9-MSCs and BMSCs were pretreated with $10 \mathrm{U} / \mathrm{mL}$ IFN- $\gamma$ and T-cell proliferation was assessed after cellular or mitogen stimuli. Results of oneway MLR showed that both pretreated H9-MSCs and BMSCs failed to generate the proliferative response of $\mathrm{T}$ cells (Fig. 6A). Two-way MLR assay showed that the comparable suppressive capacity of H9-MSCs and BMSCs inhibiting T-cell proliferation was presented at a cell number of $1 \times 10^{3}$ $(* p<0.05)$ and more pronounced at $1 \times 10^{4}$ and $1 \times 10^{5}$ $\left({ }^{\#} p<0.01\right)$ (Fig. 6B). Also, both pretreated H9-MSCs and BMSCs could suppress the PHA-induced proliferation of lymphocytes at a cell number of $1 \times 10^{3}$ and $1 \times 10^{4}(* p<0.05$, Fig. 6C). There was no significant difference between H9MSCs and BMSCs for their suppressive effects. 

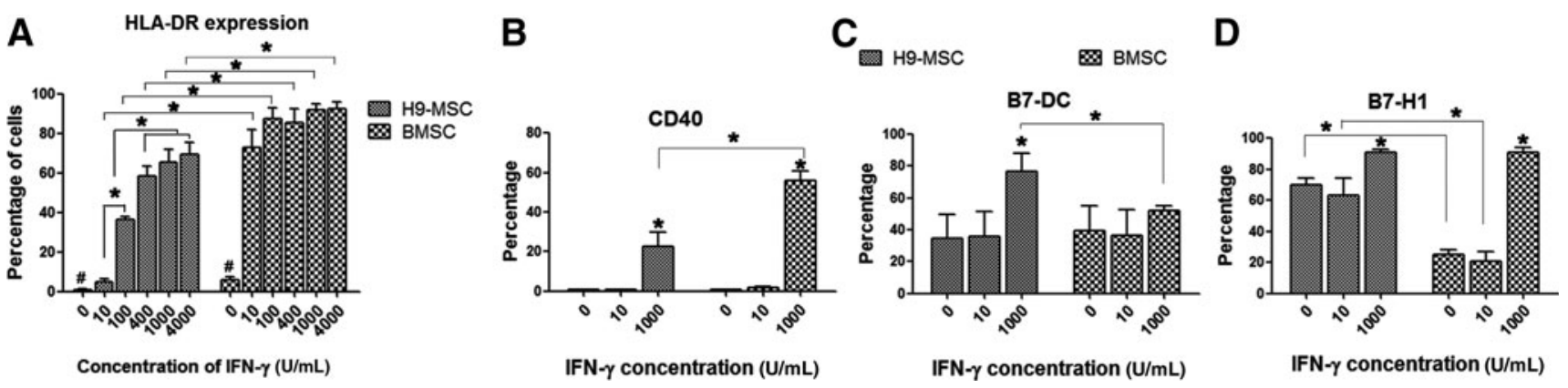

FIG. 5. Expression of immunological markers of H9-MSCs and BMSCs in response to IFN- $\gamma$ stimuli. (A) IFN- $\gamma$ could enhance the expression of HLA-DR on H9-MSCs and BMSCs with concentrations from 10 to $1000 \mathrm{U} / \mathrm{mL}$ in a dosedependent manner $\left({ }^{\#} p<0.01 ; * p<0.05\right)$. Results summarized from three independent experiments demonstrated that percentages of HLA-DR-positive cells were significantly higher in BMSCs than in H9-MSCs in response to IFN- $\gamma$ stimulation with concentrations ranging from 10 to $4000 \mathrm{U} / \mathrm{mL}\left({ }^{*} p<0.05\right)$. (B) Expressions of CD40 on H9-MSCs and BMSCs were not elicited by low dose of IFN- $\gamma(10 \mathrm{U} / \mathrm{mL})$. BMSCs showed a rapid increase in the CD40 expression after treatment with $1000 \mathrm{U} / \mathrm{mL}$ IFN- $\gamma$. A mild increase was observed in H9-MSCs treated with $1000 \mathrm{U} / \mathrm{mL}$ IFN- $\gamma$. Results summarized from three independent experiments demonstrated that percentage of CD40-positive cells was significantly higher in BMSCs than in H9-MSCs in response to $1000 \mathrm{U} / \mathrm{mL}$ IFN- $\gamma$ stimulation $\left({ }^{*} p<0.05\right)$. (C) IFN- $\gamma$ at $1000 \mathrm{U} / \mathrm{mL}$ could significantly elevate the percentage of B7-DC-positive cells in H9-MSCs, but not in BMSCs. The percentage of B7-DC-positive cells in H9MSCs was significantly increased and was significantly higher than in BMSCs after $1000 \mathrm{U} / \mathrm{mL}$ IFN- $\gamma$ treatment $(* p<0.05)$. (D) The percentages of B7-H1-positive cells in H9-MSCs were significantly higher $\left({ }^{*} p<0.05\right)$ than in BMSCs. IFN- $\gamma$ at $1000 \mathrm{U} / \mathrm{mL}$ significantly increased the percentages of B7-H1-positive cells in H9-MSCs and BMSCs and no significant differences were observed between H9-MSCs and BMSCs. IFN- $\gamma$, interferon gamma.

\section{Expression of genes encoding components of the IFN- $\gamma$ signaling pathways in H9-MSCs and BMSCs}

To explore the mechanism underlying the different responsiveness of H9-MSCs and BMSCs to IFN- $\gamma$-induced HLA-DR expression, we analyzed mRNA expressions of molecules that were involved in IFN- $\gamma$ signaling pathways by quantitative real-time PCR (Fig. 7A). The expressions of HLA-DR and CIITA (the mast regulator that determines the transcription level of MHC-II) were upregulated in both H9MSCs and BMSCs in an IFN- $\gamma$ dose-dependent manner
( ${ }^{\#} p<0.05$ for H9-MSCs treated with $0 \mathrm{U}$ and $10 \mathrm{U} / \mathrm{mL}$ IFN- $\gamma$ vs. H9-MSCs treated with $100 \mathrm{U}$ and $1000 \mathrm{U} / \mathrm{mL}$ IFN- $\gamma$; ${ }^{\Delta} p<0.05$ between BMSCs without IFN- $\gamma$ treatment vs. BMSCs with IFN- $\gamma$ treatment; ${ }^{\S} p<0.05$ between BMSCs treated with $10 \mathrm{U} / \mathrm{mL}$ IFN- $\gamma$ vs. BMSCs treated with $100 \mathrm{U}$ and $1000 \mathrm{U} / \mathrm{mL}$ IFN- $\gamma$ ) and were significantly higher in BMSCs than in H9-MSCs $(* p<0.05)$. Expression of $I F N G R 1, I F N G R 2$, IRF1, and IRF2, which are CIITA upstream signaling molecules involved in Janus kinase/signal transducers and activators of transcription (JAK/STAT) pathway, was evaluated as well. Expressions of IRF1 and
A

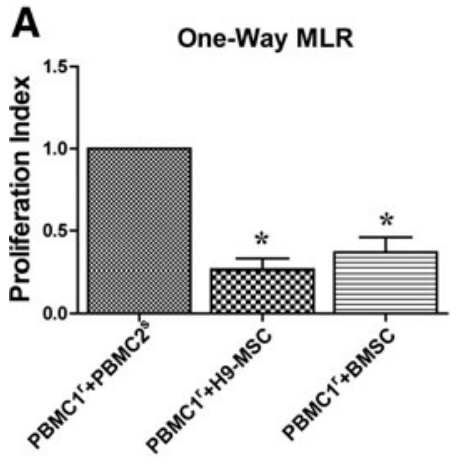

B

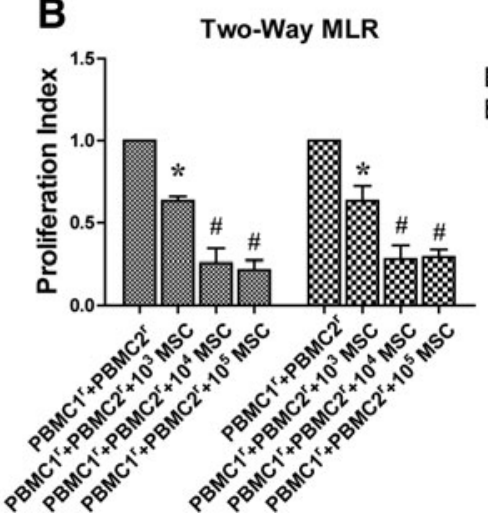

H9-MSC BMSC

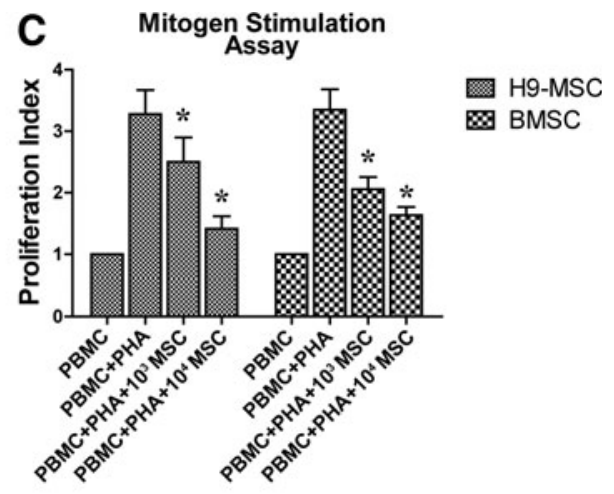

FIG. 6. Effects H9-MSCs and BMSCs pretreated with IFN- $\gamma$ on MLR and mitogen-stimulated cultures. (A) Pretreatment of H9-MSCs and BMSCs with $10 \mathrm{U} / \mathrm{mL}$ IFN- $\gamma$ failed to elicit lymphocyte proliferation. PBMC1 and PBMC2 represented PBMCs isolated from two unrelated individuals. Group coculturing PBMC1 ${ }^{\mathrm{r}}$ and $\mathrm{PBMC} 2^{\mathrm{s}}$ was used as the positive control. (B) H9-MSCs and BMSCs could inhibit lymphocyte proliferation in a two-way MLR culture in a cell number-dependent manner. Inhibitory effects of H9-MSCs and BMSCs were observed with cell number at $10^{3}(* p<0.05)$. The suppressive effects were more pronounced by H9-MSCs and BMSCs with cell number at $10^{4}$ and $10^{5}\left({ }^{\#} p<0.01\right)$. No significant difference for the immunosuppressive effects of H9-MSCs and BMSCs was observed. (C) Analysis of the immunosuppressive effects of H9-MSCs and BMSCs on PBMC proliferation induced by PHA. Inhibition effects were observed in groups coculturing $1 \times 10^{3}$ or $1 \times 10^{4} \mathrm{H} 9$-MSCs and BMSCs with $1 \times 10^{5}$ PHA-activated PBMCs $(* p<0.05)$. 


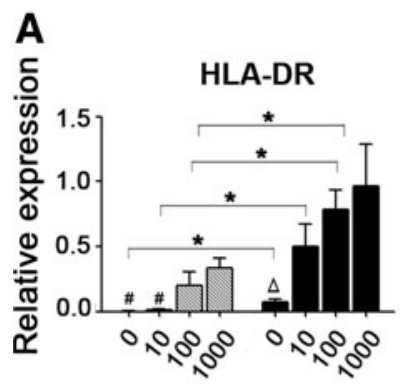

IFN- $\gamma$ concentration $(\mathrm{U} / \mathrm{mL})$

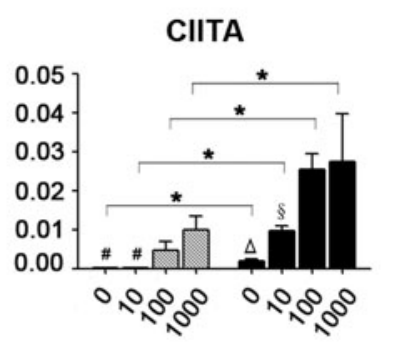

IFN- $\gamma$ concentration $(\mathrm{U} / \mathrm{mL})$

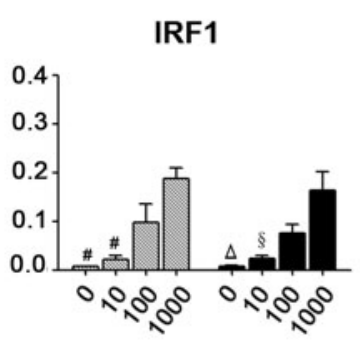

IFN- $\gamma$ concentration $(\mathrm{U} / \mathrm{mL})$

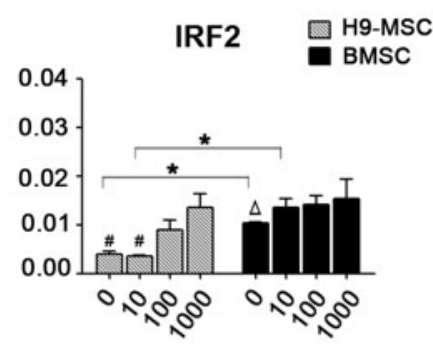

IFN- $\gamma$ concentration $(\mathrm{U} / \mathrm{mL})$
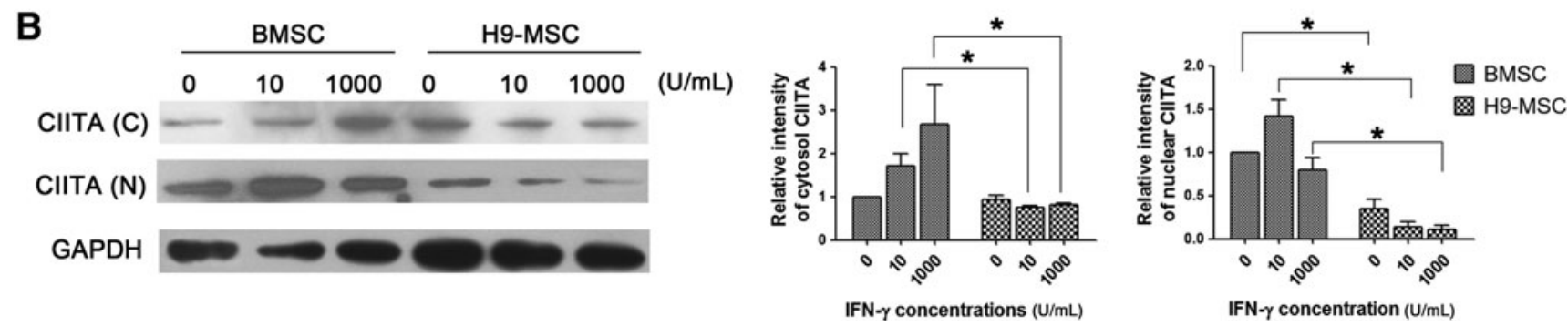

FIG. 7. Real-time PCR and western blot analysis for the expressions of molecules involved in the IFN- $\gamma$-JAK/STAT pathway in response to IFN- $\gamma$ stimulation. (A) Expressions of $H L A-D R, C I I T A, I R F 1$, and IRF2 were significantly increased in both H9-MSCs and BMSCs by IFN- $\gamma$ in a dose-dependent manner ( ${ }^{\#} p<0.05$ between H9-MSCs treated with 0 U or 10 U/ mL IFN- $\gamma$ vs. H9-MSCs treated with $100 \mathrm{U}$ or $1000 \mathrm{U} / \mathrm{mL}$ IFN- $\gamma ;{ }^{\Delta} p<0.05$ between BMSCs without IFN- $\gamma$ treatment vs. BMSCs with IFN- $\gamma$ treatment; ${ }^{\S} p<0.05$ between BMSCs treated with $10 \mathrm{U} / \mathrm{mL}$ IFN- $\gamma$ vs. BMSCs treated with $100 \mathrm{U}$ and $1000 \mathrm{U} / \mathrm{mL}$ IFN- $\gamma$ ). Expressions of $H L A-D R$ and CIITA were significantly higher in BMSCs than in H9-MSCs in response to different doses of IFN- $\gamma$ stimuli $\left({ }^{*} p<0.05\right)$, whereas expression of IRF2 was significantly higher in BMSCs than in H9MSCs in response to 0 and $10 \mathrm{U} / \mathrm{mL}$ of IFN- $\gamma$ stimuli $(* p<0.05)$. (B) Western blot analysis for semiquantification of CIITA proteins in the cytoplasm and nuclear extracts in H9-MSC and BMSC in response to IFN- $\gamma$ stimulation $(0 \mathrm{U}, 10 \mathrm{U}, 1000 \mathrm{U} /$ $\mathrm{mL})$. CIITA (C) represents CIITA in the cytoplasm fraction, whereas CIITA (N) represents CIITA in the nuclear fraction. For semiquantification, western blot analysis was carried out for four times and the levels of CIITA proteins were normalized to GAPDH. The amount of CIITA (C) was significantly lower in H9-MSCs than in BMSCs after exposure to IFN- $\gamma$, whereas CIITA (N) was significantly lower in H9-MSCs than in BMSCs with or without IFN- $\gamma$ treatment $(* p<0.05)$. CIITA, class II transactivator.

IRF2 were significantly enhanced in both H9-MSCs and BMSCs after IFN- $\gamma$ treatment, but IRF2 expression was significantly lower in H9-MSCs than in BMSCs with 0 and $10 \mathrm{U} / \mathrm{mL}$ IFN- $\gamma$ treatment $(* p<0.05)$. Besides, no significant difference was observed for the expression of IFNGRI, $I F N G R 2$, and CIITA binding proteins, including CREB1, RFX factors (RFX5, RFXAP, RFXANK), and NF-Y factors (NFYA, NFYB, and NFYC) in H9-MSCs and BMSCs after IFN- $\gamma$ stimulations (Supplementary Fig. S3).

As nuclear translocation of CIITA plays an important role for its function, western blot analysis was used to semiquantify the amount of CIITA proteins in the cytoplasm and nuclear extracts of H9-MSCs and BMSCs (Fig. 7B). CIITA (C) represents CIITA in the cytoplasm fraction, whereas CIITA $(\mathrm{N})$ represents CIITA in the nuclear fraction. Exposure to low-dose $(10 \mathrm{U} / \mathrm{mL})$ IFN- $\gamma$ significantly enhanced the amount of CIITA proteins in both the nuclear and cytoplasm fractions of BMSCs $(p<0.05)$. However, CIITA proteins showed cytoplasm retention in BMSCs after exposure to high-dose $(1000 \mathrm{U} / \mathrm{mL}) \mathrm{IFN}-\gamma$. In contrast, IFN- $\gamma$ at two different concentrations failed to promote CIITA protein synthesis and nuclear translocation in H9-MSCs. Moreover, the amount of cytoplasmic CIITA was significantly lower in H9-MSCs than in BMSCs after exposure to IFN- $\gamma$, whereas nuclear CIITA was significantly lower in
H9-MSCs than in BMSCs with or without IFN- $\gamma$ stimulation $(* p<0.05)$.

\section{Discussion}

The hESCs have been considered as an alternative source for MSCs, which have promising therapeutic potentials for regenerative medicine and immunotherapy. To compare the immunological characteristics of MSCs derived from hESCs with tissue-derived MSCs is crucial for the applications. In the present study, H9-MSCs were successfully derived from H9 hESCs through an EB outgrowth method and their immunological characteristics were compared with BMSCs. Our results demonstrated that H9-MSCs and BMSCs with or without IFN- $\gamma$ pretreatment had similar immunogenicity and inhibitory effects on lymphocyte proliferation induced by cellular and mitogenic stimuli. However, expression profiles of immunological markers in H9-MSCs and BMSCs showed significantly higher expression of B7-H1, but lower expression of HLA-DR in H9-MSCs than in BMSCs. IFN- $\gamma$ stimulation assay suggested that H9-MSCs were less susceptible to IFN- $\gamma$-induced HLA-DR expression than BMSCs. Further detection of expression of molecules involved in IFN- $\gamma$ signaling pathways suggested that the lower expression of HLADR in H9-MSCs than in BMSCs could be partially attributed 
to the lower expression levels of CIITA and IRF2, and the less nuclear translocation of CIITA.

It is well-known that T-lymphocyte activation required two signals. The first signal is provided by an interaction of the T-cell receptor with antigenic peptide presented by MHC-II molecules, and the second costimulatory signal can only be delivered by costimulatory molecules. ${ }^{18}$ Indeed, a recent study reported that a significant increase in the proliferation of antigen-challenged lymphocytes from allergic rhinitis subjects is correlated with increased expressions of MHC-II and CD86 on MSCs in response to increased production of inflammatory cytokines from T cells. ${ }^{50}$ IFN- $\gamma$ is a proinflammatory cytokine produced by activated immune cells in both innate and adaptive immune responses. ${ }^{19}$ It has been reported that IFN- $\gamma$ can markedly stimulate or increase the expression of MHC-II molecules in many cell types, including MSCs. ${ }^{16,19,20}$ Our finding that H9-MSCs and BMSCs pretreated with IFN- $\gamma$ had a dramatic increasing of HLA-DR and failed to generate T-cell proliferation in vitro could be explained by the lack of expression of costimulatory markers. Interestingly, the prompt emergences of T-cell costimulatory molecule CD40 on BMSCs and H9-MSCs after incubating with $1000 \mathrm{U} / \mathrm{mL}$ IFN- $\gamma$ were observed in our study. Together with the reports that administration of allogeneic MSC after IFN- $\gamma$ stimulation is in fact immunogenic in vivo, ${ }^{51,52}$ our results suggested that MSCs might not be totally immunoprivileged in inflammatory conditions. Moreover, we first reported that H9-MSCs expressed a significantly higher level of B7-H1 than BMSCs did and more sensitive to IFN- $\gamma$-induced expression of B7-DC after exposure to $1000 \mathrm{U} / \mathrm{mL} \mathrm{IFN}-\gamma$. B7-H1 and B7-DC were found to serve as coinhibitory molecules by binding to their receptor CD279 (PD-1) and suppressing the lymphocyte proliferation. ${ }^{53,54}$ Hence, it was suggested that the immunosuppressive ability of H9-MSCs might be activated earlier and easier compared with BMSCs.

IFN $-\gamma$ signaling is mediated by the JAK/STAT signaling pathway. ${ }^{55}$ Binding of IFN- $\gamma$ to its cognition receptors IFN$\gamma \mathrm{R} 1$ and IFN- $\gamma \mathrm{R} 2$ results in receptor dimerization and subsequent activation of receptor-associated JAK1 and JAK2, leading to phosphorylation and nuclear translocation of STAT-1. STAT-1 cooperates with its downstream transcription factor interferon regulatory factor 1 (IRF1), ubiquitously expressed factors USF-1 and IRF2 to activate the transcription of CIITA. CIITA in turn forms transcriptosome with the heterotrimeric NF-Y transcription factor, CREB, and the trimeric RFX complex to regulate transcription of the MHC-II genes. ${ }^{56}$ Our findings first showed that the expressions of signaling molecules involved in the IFN- $\gamma$ signaling pathway were comparable in H9-MSCs and in BMSCs with or without IFN- $\gamma$ treatment, except for IRF2 and CIITA. CIITA is the master regulator that determines the transcription level of MHC-II, ${ }^{57}$ and its nuclear translocation is crucial to its function. In our study, low concentration $(10 \mathrm{U} / \mathrm{mL})$ of IFN- $\gamma$ treatment enhanced nuclear translocation of CIITA protein, whereas high concentration $(1000 \mathrm{U} / \mathrm{mL})$ of IFN- $\gamma$ treatment resulted in cytoplasmic retention of CIITA in BMSCs, consistent with a previous report. ${ }^{21}$ However, we did not observe obvious nuclear translocation of CIITA in H9-MSCs exposed to either low or high concentrations of IFN- $\gamma$. CIITA is composed of four functional domains: acidic transactivation domain, proline/ serine/threonine (PST)-rich domain, GTP binding domain (GBD), and Leucine-rich repeats (LRR), and three nuclear localization regions. ${ }^{58}$ Previous studies demonstrated that LRR of CIITA controlled its rate of nuclear accumulation. ${ }^{59}$ Mutations in GBD and LRR, as well as hypophosphorylation in the PST domain could impair the nuclear translocation of CIITA. ${ }^{60,61}$ Thus, it could be speculated that the structures or epigenetic modification of the functional domains of CIITA in hESC-derived MSCs might be distinct from BMSCs and responsible for the decreased nuclear translocation of CIITA. Further investigations are needed to determine the underlying mechanism.

In conclusion, we demonstrated that hESC-derived MSCs shared similar immunoprivileged status and immunosuppressive abilities as BMSCs. Also, the evidences that H9-MSCs differ from BMSCs in the expression profile of immunological markers and their responsiveness to the proinflammatory cytokine IFN- $\gamma$, suggested that MSCs derived from hESCs could be a safe and efficient candidate for MSC treatment in patients with inflammatory disorders. Moreover, we first reported that H9-MSCs were less susceptible to IFN- $\gamma$-induced HLA-DR expression than BMSCs by expressing lower mRNA levels of IRF2 and CIITA, and less nuclear translocation of CIITA proteins. These data provide a new insight into the molecular mechanism that determines the immunological characteristics of MSCs from different developmental origins.

\section{Acknowledgments}

The authors thank Dr. Li Mingming at the Faculty of Dentistry, National University of Singapore for his help in the techniques for differentiation of hESCs into MSCs. This work was supported by grants from the National Natural Science Foundation of China $(31201102,30871433$, and $31071305)$ and the Foundation of International Technical Cooperation Projects (2011DFA32190).

\section{Disclosure Statement}

No competing financial interests exist.

\section{References}

1. Ghannam, S., Bouffi, C., Djouad, F., Jorgensen, C., and Noël, D. Immunosuppression by mesenchymal stem cells: mechanisms and clinical applications. Stem Cell Res Ther 1, 2, 2010.

2. Nombela-Arrieta, C., Ritz, J., and Silberstein, L.E. The elusive nature and function of mesenchymal stem cells. Nat Rev Mol Cell Biol 12, 126, 2011.

3. Lennon, D.P., and Caplan, A.I. Isolation of human marrowderived mesenchymal stem cells. Exp Hematol 34, 1604, 2006.

4. In't Anker, P.S., Scherjon, S.A., Kleijburg-van der Keur, C., de Groot-Swings, G.M., Claas, F.H., Fibbe, W.E., and Kanhai, H.H. Isolation of mesenchymal stem cells of fetal or maternal origin from human placenta. Stem Cells 22, 1338, 2004.

5. Mauney, J.R., Volloch, V., and Kaplan, D.L. Role of adult mesenchymal stem cells in bone tissue engineering applications: current status and future prospects. Tissue Eng 11, 787, 2005.

6. Bradley, J.A., Bolton, E.M., and Pedersen, R.A. Stem cell medicine encounters the immune system. Nat Rev Immunol 2, 859, 2002. 
7. Kimbrel, E.A., Kouris, N.A., Yavanian, G.J., Chu, J., Qin, Y., Chan, A., Singh, R.P., McCurdy, D., Gordon, L., Levinson, R.D., and Lanza, R. Mesenchymal stem cell population derived from human pluripotent stem cells displays potent immunomodulatory and therapeutic properties. Stem Cells Dev 23, 1611, 2014.

8. Rao, M.S., and Mattson, M.P. Stem cells and aging: expanding the possibilities. Mech Ageing Dev 122, 713, 2001.

9. Stenderup, K., Justesen, J., Clausen, C., and Kassem, M. Aging is associated with decreased maximal life span and accelerated senescence of bone marrow stromal cells. Bone 33, 919, 2003.

10. Thomson, J.A., Itskovitz-Eldor, J., Shapiro, S.S., Waknitz, M.A., Swiergiel, J.J., Marshall, V.S., and Jones, J.M. Embryonic stem cell lines derived from human blastocysts. Science 282, 1145, 1998.

11. Tan, Z., Su, Z.Y., Wu, R.R., Gu, B., Liu, Y.K., Zhao, X.L., and Zhang, M. Immunomodulative effects of mesenchymal stem cells derived from human embryonic stem cells in vivo and in vitro. J Zhejiang Univ Sci B 12, 18, 2011.

12. Trivedi, P., and Hematti, P. Derivation and immunological characterization of mesenchymal stromal cells from human embryonic stem cells. Exp Hematol 36, 350, 2008.

13. Sánchez, L., Gutierrez-Aranda, I., Ligero, G., Rubio, R., Muñoz-López, M., García-Pérez, J.L., Ramos, V., Real, P.J., Bueno, C., Rodríguez, R., Delgado, M., and Menendez, P. Enrichment of human ESC-derived multipotent mesenchymal stem cells with immunosuppressive and anti-inflammatory properties capable to protect against experimental inflammatory bowel disease. Stem Cells 29, 251, 2011.

14. Yen, B.L., Chang, C.J., Liu, K.J., Chen, Y.C., Hu, H.I., Bai, C.H., and Yen, M.L. Brief report-human embryonic stem cell-derived mesenchymal progenitors possess strong immunosuppressive effects toward natural killer cells as well as T lymphocytes. Stem Cells 27, 451, 2009.

15. Lee, E.J., Lee, H.N., Kang, H.J., Kim, K.H., Hur, J., Cho, H.J., Lee, J., Chung, H.M., Cho, J., Cho, M.Y., Oh, S.K., Moon, S.Y., Park, Y.B., and Kim, H.S. Novel embryoid body-based method to derive mesenchymal stem cells from human embryonic stem cells. Tissue Eng Part A 16, 705, 2010.

16. Chan, W.K., Lau, A.S., Li, J.C., Law, H.K., Lau, Y.L., and Chan, G.C. MHC expression kinetics and immunogenicity of mesenchymal stromal cells after short-term IFN-gamma challenge. Exp Hematol 36, 1545, 2008.

17. Janeway, C.A., Jr., Travers, P., Walport, M., et al. The major histocompatibility complex and its functions. In: Immunobiology: The Immune System in Health and Disease. 5th edition. New York: Garland Science, 2001. Available from: http://www.ncbi.nlm.nih.gov/books/NBK27156/

18. Collins, M., Ling, V., and Carreno, B.M. The B7 family of immune-regulatory ligands. Genome Biol 6, 223, 2005.

19. Schroder, K., Hertzog, P.J., Ravasi, T., and Hume, D.A. Interferon-gamma: an overview of signals, mechanisms and functions. J Leukoc Biol 75, 163, 2004.

20. Romieu-Mourez, R., François, M., Boivin, M.N., Stagg, J., and Galipeau, J. Regulation of MHC class II expression and antigen processing in murine and human mesenchymal stromal cells by IFN-gamma, TGF-beta, and cell density. J Immunol 179, 1549, 2007.

21. Tang, K.C., Trzaska, K.A., Smirnov, S.V., Kotenko, S.V., Schwander, S.K., Ellner, J.J., and Rameshwar, P. Downregulation of MHC II in mesenchymal stem cells at high IFN-gamma can be partly explained by cytoplasmic retention of CIITA. J Immunol 180, 1826, 2008.
22. Ren, G., Zhang, L., Zhao, X., Xu, G., Zhang, Y., Roberts, A.I., Zhao, R.C., and Shi, Y. Mesenchymal stem cellmediated immunosuppression occurs via concerted action of chemokines and nitric oxide. Cell Stem Cell 2, 141, 2008.

23. Polchert, D., Sobinsky, J., Douglas, G., Kidd, M., Moadsiri, A., Reina, E., Genrich, K., Mehrotra, S., Setty, S., Smith, B., and Bartholomew, A. IFN-gamma activation of mesenchymal stem cells for treatment and prevention of graft versus host disease. Eur J Immunol 38, 1745, 2008.

24. Stagg, J., Pommey, S., Eliopoulos, N., and Galipeau, J. Interferon- $\gamma$-stimulated marrow stromal cells: a new type of nonhematopoietic antigen-presenting cell. Blood 107, 2570, 2006.

25. Chan, J.L., Tang, K.C., Patel, A.P., Bonilla, L.M., Pierobon, N., Ponzio, N.M., and Rameshwar, P. Antigenpresenting property of mesenchymal stem cells occurs during a narrow window at low levels of interferon-gamma. Blood 107, 4817, 2006.

26. Eliopoulos, N., Stagg, J., Lejeune, L., Pommey, S., and Galipeau, J. Allogeneic marrow stromal cells are immune rejected by MHC class I- and class II-mismatched recipient mice. Blood 106, 4057, 2005.

27. Williams, A.R., and Hare, J.M. Mesenchymal stem cells: biology, pathophysiology, translational findings, and therapeutic implications for cardiac disease. Circ Res 109, 923, 2011.

28. Dazzi, F., Ramasamy, R., Glennie, S., Jones, S.P., and Roberts I. The role of mesenchymal stem cells in haemopoiesis. Blood Rev 20, 161, 2006.

29. Keating, A. Mesenchymal stromal cells. Curr Opin Hematol 13, 419, 2006.

30. Rasmusson, I., Ringden, O., Sundberg, B., and Le Blanc, K. Mesenchymal stem cells inhibit lymphocyte proliferation by mitogens and alloantigens by different mechanisms. Exp Cell Res 305, 33, 2005.

31. Van Laar, J.M., and Tyndall, A. Adult stem cells in the treatment of autoimmune diseases. Rheumatology (Oxford) 45, 1187, 2006.

32. Maitra, B., Szekely, E., Gjini, K., Laughlin, M.J., Dennis, J., Haynesworth, S.E., and Koç, O.N. Human mesenchymal stem cells support unrelated donor hematopoietic stem cells and suppress T-cell activation. Bone Marrow Transplant 33, 597, 2004.

33. Le Blanc, K., Rasmusson, I., Sundberg, B., Gotherstrom, C., Hassan, M., Uzunel, M., and Ringden, O. Treatment of severe acute graft-versus-host disease with third party haploidentical mesenchymal stem cells. Lancet 363, 1439, 2004.

34. Zappia, E., Casazza, S., Pedemonte, E., Benvenuto, F., Bonanni, I., Gerdoni, E., Giunti, D., Ceravolo, A., Cazzanti, F., Frassoni, F., et al. Mesenchymal stem cells ameliorate experimental autoimmune encephalomyelitis inducing $\mathrm{T}$ cell anergy. Blood 106, 1755, 2005.

35. Djouad, F., Fritz, V., Apparailly, F., Louis-Plence, P., Bony, C., Sany, J., Jorgensen, C., and Noel, D. Reversal of the immunosuppressive properties of mesenchymal stem cells by tumor necrosis factor alpha in collagen-induced arthritis. Arthritis Rheum 52, 1595, 2005.

36. Xu, G., Zhang, L., Ren, G., Yuan, Z., Zhang, Y., Zhao, R.C., and Shi, Y. Immunosuppressive properties of cloned bone marrow mesenchymal stem cells. Cell Res 17, 240, 2007.

37. English, K., Ryan, J.M., Tobin, L., Murphy, M.J., Barry, F.P., and Mahon, B.P. Cell contact, prostaglandin E(2) and transforming growth factor beta 1 play non-redundant roles in human mesenchymal stem cell induction of $\mathrm{CD} 4+$ CD25(High) forkhead box P3 + regulatory $\mathrm{T}$ cells. Clin Exp Immunol 156, 149, 2009. 
38. Djouad, F., Charbonnier, L.M., Bouffi, C., et al. Mesenchymal stem cells inhibit the differentiation of dendritic cells through an Il-6-dependent mechanism. Stem Cells 25, 2025, 2007.

39. Groh, M.E., Maitra, B., Szekely, E., and Koc, O.N. Human mesenchymal stem cells require monocyte-mediated activation to suppress alloreactive T cells. Exp Hematol 33, 928, 2005.

40. Patel, S.A., Meyer, J.R., Greco, S.J., Corcoran, K.E., Bryan, M., and Rameshwar, P. Mesenchymal stem cells protect breast cancer cells through regulatory $\mathrm{T}$ cells: role of mesenchymal stem cell-derived TGF-beta. J Immunol 184, 5885, 2010.

41. Di Nicola, M., Carlo-Stella, C., Magni, M., Milanesi, M., Longoni, P.D., Matteucci, P., Grisanti, S., and Gianni, A.M. Human bone marrow stromal cells suppress T-lymphocyte proliferation induced by cellular or nonspecific mitogenic stimuli. Blood 99, 3838, 2002.

42. Sato, K., Ozaki, K., Oh, I., Meguro, A., Hatanaka, K., Nagai, T., Muroi, K., and Ozawa, K. Nitric oxide plays a critical role in suppression of $\mathrm{T}$-cell proliferation by mesenchymal stem cells. Blood 109, 228, 2007.

43. Meisel, R., Zibert, A., Laryea, M., Göbel, U., Däubener, W., and Dilloo, D. Human bone marrow stromal cells inhibit allogeneic T-cell responses by indoleamine 2,3dioxygenase-mediated tryptophan degradation. Blood 103, 4619, 2004.

44. Maby-El Hajjami, H., Amé-Thomas, P., Pangault, C., Tribut, O., DeVos, J., Jean, R., Bescher, N., Monvoisin, C., Dulong, J., Lamy, T., Fest, T., and Tarte, K. Functional alteration of the lymphoma stromal cell niche by the cytokine context: role of indoleamine-2,3 dioxygenase. Cancer Res 69, 3228, 2009.

45. Nemeth, K., Leelahavanichkul, A., Yuen, P.S., Mayer, B., Parmelee, A., Doi, K., Robey, P.G., Leelahavanichkul, K., Koller, B.H., Brown, J.M., Hu, X., Jelinek, I., Star, R.A., and Mezey, E. Bone marrow stromal cells attenuate sepsis via prostaglandin E2-dependent reprogramming of host macrophages to increase their interleukin-10 production. Nat Med 15, 42, 2009.

46. Spaggiari, G.M., Abdelrazik, H., Becchetti, F., and Moretta, L. MSCs inhibit monocytederived DC maturation and function by selectively interfering with the generation of immature DCs: central role of MSC-derived prostaglandin E2. Blood 113, 6576, 2009.

47. Fu, X., Toh, W.S., Liu, H., Lu, K., Li, M., and Cao, T. Establishment of clinically compliant human embryonic stem cells in an autologous feeder-free system. Tissue Eng Part C Methods 17, 927, 2011.

48. Hu, J., Smith, L.A., Feng, K., Liu, X., Sun, H., and Ma, P.X. Response of human embryonic stem cell-derived mesenchymal stem cells to osteogenic factors and architectures of materials during in vitro osteogenesis. Tissue Eng Part A 16, 3507, 2010.

49. Liu, H., Kemeny, D.M., Heng, B.C., Ouyang, H.W., Melendez, A.J., and Cao, T. The immunogenicity and immunomodulatory function of osteogenic cells differentiated from mesenchymal stem cells. J Immunol 176, 2864, 2006.

50. Desai, M.B., Gavrilova, T., Liu, J., Patel, S.A., Kartan, S., Greco, S.J., Capitle, E., and Rameshwar, P. Pollen-induced antigen presentation by mesenchymal stem cells and T cells from allergic rhinitis. Clin Transl Immunol 2, e7, 2013.

51. Rafei, M., Birman, E., Forner, K., and Galipeau, J. Allogeneicmesenchymal stem cells for treatment of experimental autoimmune encephalomyelitis. Mol Ther 17, 1799, 2009.
52. Schu, S., Nosov, M., O’Flynn, L., Shaw, G., Treacy, O., Barry, F., Murphy, M., O'Brien, T., and Ritter, T. Immunogenicity of allogeneic mesenchymal stem cells. J Cell Mol Med 16, 2094, 2012.

53. Augello, A., Tasso, R., Negrini, S.M., Amateis, A., Indiveri, F., Cancedda, R., and Pennesi, G. Bone marrow mesenchymal progenitor cells inhibit lymphocyte proliferation by activation of the programmed death 1 pathway. Eur J Immunol 35, 1482, 2005.

54. Sheng, H., Wang, Y., Jin, Y., Zhang, Q., Zhang, Y., et al. A critical role of IFN gamma in priming MSC-mediated suppression of T cell proliferation through up-regulation of B7-H1. Cell Res 18, 846, 2008.

55. Murphy, S.P., Choi, J.C., and Holtz, R. Regulation of major histocompatibility complex class II gene expression in trophoblast cells. Reprod Biol Endocrinol 2, 52, 2004.

56. Chang, C.H., Fontes, J.D., Peterlin, M., and Flavell, R.A. Class II transactivator (CIITA) is sufficient for the inducible expression of major histocompatibility complex class II genes. J Exp Med 180, 1367, 1994.

57. Muhlethaler-Mottet, A., Di Berardino, W., Otten, L.A., and Mach, B. Activation of the MHC class II transactivator CIITA by interferon-gamma requires cooperative interaction between Stat1 and USF-1. Immunity 8, 157, 1998.

58. Harton, J.A., O'Connor, W., Jr., Conti, B.J., Linhoff, M.W., and Ting, J.P. Leucine-rich repeats of the class II transactivator control its rate of nuclear accumulation. Hum Immunol 63, 588, 2002.

59. Linhoff, M.W., Harton, J.A., Cressman, D.E., Martin, B.K., and Ting, J.P. Two distinct domains within CIITA mediate self-association: involvement of the GTP-binding and leucine-rich repeat domains. Mol Cell Biol 21, 3001.

60. Chin, K.C., Li, G.G., and Ting, J.P. Importance of acidic, proline/serine/threonine-rich, and GTP-binding regions in the major histocompatibility complex class II transactivator: generation of transdominant-negative mutants. Proc Natl Acad Sci U S A 94, 2501, 1997.

61. Fontes, J.D., Jiang, B., and Peterlin, B.M. The class II transactivator CIITA interacts with the TBP-associated factor TAFII32. Nucleic Acids Res 25, 2522, 1997.

Address correspondence to: Ran Xiao, PhD, DDS

Research Center of Plastic Surgery Hospital Chinese Academy of Medical Sciences Peking Union Medical College Beijing 100144

P.R. China

E-mail: xiaoran@pumc.edu.cn

Wen-Jie Zhang, MD, PhD Stem Cell Laboratory Department of Plastic and Reconstructive Surgery Shanghai 9th People's Hospital Shanghai Jiao Tong University School of Medicine Shanghai 200011 P.R. China

E-mail: wenjieboshi@aliyun.com

Received: October 18, 2013

Accepted: September 15, 2014

Online Publication Date: January 7, 2015 